\title{
Postoperative esophageal leak management with the Polyflex esophageal stent
}

\author{
Richard K. Freeman, MD, ${ }^{a}$ Anthony J. Ascioti, MD, ${ }^{a}$ and Thomas C. Wozniak, MD ${ }^{b}$
}

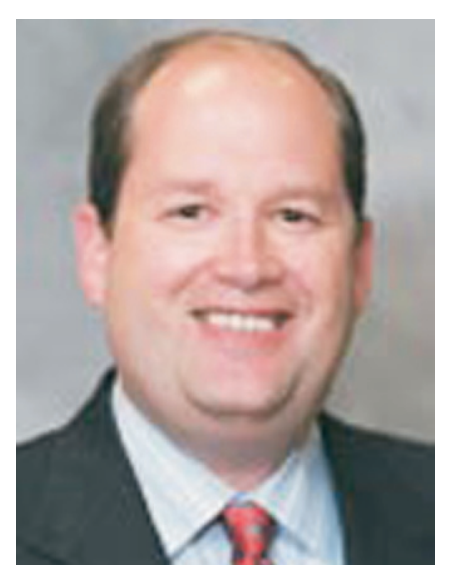

Dr Freeman
Objective: Leak after esophageal anastomosis or perforation repair prolongs hospitalization, prevents oral hydration and nutrition, and can produce localized infection or sepsis. This investigation reviews our experience treating postoperative esophageal leaks with the Polyflex esophageal stent (Boston Scientific, Natick, Mass).

Methods: Over a 30-month period, patients with a postoperative esophageal leak were treated with the Polyflex stent for leak occlusion. Leak occlusion was confirmed by means of esophagraphy. Patients were followed until their stent was removed and their esophageal leak had resolved.

Results: Twenty-one patients had 27 stents placed for leak occlusion after esophagectomy $(n=5)$, esophageal perforation $(n=5)$, surgical $(n=4)$ or endoscopic $(\mathrm{n}=2)$ antireflux procedure, and esophageal diverticulectomy $(\mathrm{n}=3)$ or myotomy $(\mathrm{n}=2)$. The mean interval between surgical intervention and stent placement was $12 \pm 8$ days (range, 3-31 days). Occlusion of the leak occurred in 20 patients. One patient experienced a dehiscence of the surgical esophageal perforation repair requiring esophageal diversion. Stent migration requiring repositioning $(n=3)$ or replacement $(\mathrm{n}=4)$ occurred in $5(24 \%)$ patients. Twenty $(95 \%)$ stents were removed without residual leak (mean, $51 \pm 43$ days; range, 15-175 days). One patient had a stricture after stent removal that required endoscopic dilatation. One patient in this series died.

Conclusions: The Polyflex esophageal stent is an effective method for occluding a postoperative esophageal leak. It rapidly eliminates contamination of the mediastinum, pleura, and peritoneum; allows oral hydration and nutrition; and is easily removable. These stents also offer an appealing alternative to traditional esophageal diversion and subsequent reconstruction in patients with a persistent esophageal leak.

From the Departments of Thoracic and Cardiovascular Surgery, St Vincent Hospital ${ }^{\text {a }}$ and Methodist Hospital, ${ }^{\mathrm{b}}$ Indianapolis, Ind.

Read at the Eighty-sixth Annual Meeting of The American Association for Thoracic Surgery, Philadelphia, Pa, April 29-May 3, 2006.

Received for publication April 25, 2006; revisions received Sept 26, 2006; accepted for publication Oct 9, 2006.

Address for reprints: Richard K. Freeman, MD, 8433 Harcourt Rd, Indianapolis, IN 46260 (E-mail: RFreeman@corvascmds. com).

J Thorac Cardiovasc Surg 2007;133:333-8

$0022-5223 / \$ 32.00$

Copyright $(C) 2007$ by The American Association for Thoracic Surgery

doi:10.1016/j.jtcvs.2006.10.008

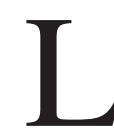
eak after esophageal anastomosis or perforation repair can be a challenge for the surgeon. Traditional therapy for a symptomatic postoperative esophageal fistula has been operative repair or, if unsuccessful, esophageal diversion. Such treatment prolongs hospitalization and significantly delays oral hydration and nutrition. In the case of subsequent unsuccessful repairs, esophageal diversion commits

Endoluminal esophageal stents have been available for many years and have been used to palliate unresectable esophageal malignancies with dysphagia. Unfortunately, the characteristics of the material of which stents were made caused them to be difficult to insert and remove and resulted in significant complications, such as stent migration, fistula formation or enlargement, and bleeding. However, since esophageal stents made of materials that make them easier to place and remove, are significantly more flexible, and exert less radial force and remain occlusive have become available, recent reports of their use to treat symptomatic esophageal anastomotic leak after cancer resection have been published. ${ }^{1,2}$ This investigation reviews our experience treating recalcitrant postoperative esophageal fistulae endothe patient to further surgical intervention to re-establish foregut continuity. 
scopically using an occlusive, silicon-coated esophageal stent (Polyflex; Boston Scientific, Natick, Mass).

\section{Materials and Methods}

Over a 30-month period, patients who experienced a postoperative esophageal leak at either of 2 tertiary-care hospitals were offered participation in an institutional review board-approved protocol using an endoluminal esophageal stent to treat their fistula, a use of the Polyflex stent not currently recognized by the Food and Drug Administration. Patients with a documented esophageal leak that had recurred after at least 1 operative repair were eligible for participation in this investigation. For the purposes of this investigation, patients with an esophageal perforation or esophageal malignancies not previously treated with surgical intervention were excluded. Also excluded from participation were patients with an anastomotic disruption or ischemic esophageal conduit that would necessitate esophageal diversion. The presence of an esophageal fistula was documented and localized by means of gastrograffin esophagraphy, barium esophagraphy, or both before any treatment. Additionally, all patients being considered for stent placement underwent computer-aided tomographic imaging of the neck, chest, and abdomen.

All esophageal stents were placed in the operating room by a thoracic surgeon using general endotracheal anesthesia and fluoroscopy after flexible esophagoscopy. Adequate drainage of infected areas was also simultaneously achieved. Fistula occlusion was confirmed by means of contrast esophagraphy a minimum of 48 hours after stent placement or when the patient was able to participate in the examination. In the absence of a continued leak, patients who were able were begun on a "soft mechanical" diet without bread or meat and advanced as tolerated to a "postgrastrectomy" diet.

It was the intention to remove all patients' esophageal stents after a sufficient amount of time to allow permanent fistula closure. This was individualized based on the fistula cause, anatomic location, nutritional status of the patient, and resolution of all associated infectious or septic parameters, including the resolution of any associated organ failure, but was not less than 14 days after initial stent placement. Stent removal again was carried out in the operating room after achievement of general anesthesia. Flexible esophagoscopy was performed before and after stent removal as well. An esophagraphy was again performed 24 hours after stent removal to exclude recurrent leak. Patients were followed until their esophageal fistula had resolved, their stent had been removed, and they were tolerating oral nutrition. All patients were assessed at least 1 month after stent removal for dysphagia. Continuous data for this investigation are expressed as the mean \pm standard deviation of the mean, except where otherwise indicated.

\section{Results}

During the 30-month study period, 29 patients were evaluated by the authors at either of the 2 study institutions for a postoperative esophageal fistula. Twenty-two patients met the investigation's inclusion criteria; 1 of these patients refused further intervention and was not included in this review. Thus 21 patients were available to participate. Follow-up was complete in all of these 21 patients for the
Table 1. Patient demographic

\begin{tabular}{|c|c|c|c|}
\hline Age (y) & Initial procedure & $\begin{array}{c}\text { Attempted } \\
\text { operative repairs }\end{array}$ & Fistula location \\
\hline 64 & Esophagectomy & 1 & Pleura \\
\hline 59 & Esophagectomy* & 2 & Trachea \\
\hline 51 & Esophagectomy* & 1 & Bronchus \\
\hline 67 & Esophagectomy* & 1 & Pleura \\
\hline 54 & Esophagectomy* & 1 & Bronchus \\
\hline 44 & Perforation repair & 3 & Cutaneous (neck) \\
\hline 93 & Perforation repair & 1 & Peritoneum \\
\hline 69 & Perforation repair & 1 & $\begin{array}{l}\text { Pleura and } \\
\text { peritoneum }\end{array}$ \\
\hline 82 & Perforation repair & 1 & Bronchus \\
\hline 84 & Perforation repair & 2 & Mediastinum \\
\hline 34 & Surgical antireflux & 1 & Peritoneum \\
\hline 48 & Surgical antireflux & 1 & Mediastinum \\
\hline 39 & Surgical antireflux & 1 & Peritoneum \\
\hline 49 & Surgical antireflux & 2 & $\begin{array}{l}\text { Pleura and } \\
\text { peritoneum }\end{array}$ \\
\hline 73 & Diverticulectomy & 1 & Pleura \\
\hline 66 & Diverticulectomy & 1 & Mediastinum \\
\hline 37 & Diverticulectomy & 2 & Mediastinum \\
\hline 72 & Endoscopic antireflux & 1 & Mediastinum \\
\hline 78 & Endoscopic antireflux & 1 & Peritoneum \\
\hline 33 & Esophageal myotomy & 1 & Peritoneum \\
\hline 14 & Esophageal myotomy & 4 & $\begin{array}{l}\text { Peritoneum and } \\
\text { pleura }\end{array}$ \\
\hline
\end{tabular}

Procedure, Initial surgical or endoscopic procedure; Attempted operative repairs, number of surgical procedures to repair esophageal leak/fistula before stent placement; Fistula location, distal esophageal fistula site. *Received preoperative chemotherapy and external beam radiation therapy.

study period. Their mean age was $58 \pm 20$ years (range, 14-93 years). The causes of their esophageal fistulae were esophagectomy $(\mathrm{n}=5)$, esophageal perforation repair $(\mathrm{n}=$ $5)$, surgical antireflux procedure $(n=4)$, esophageal diverticulectomy $(\mathrm{n}=3)$, endoscopic antireflux procedure $(\mathrm{n}=$ 2 ), and esophageal myotomy $(n=2$, Table 1$)$. Five patients were seen in consultation as inpatients after their original operation, and 16 patients were transferred from other hospitals before their evaluation. The mean number of attempted repairs before stent placement was $1.4 \pm 0.8$ (range, 1-4; median, 1). The mean number of days from initial surgical repair to stent placement was $12 \pm 8$ days (range, 3-31 days). Twelve (57\%) patients underwent additional procedures at the time of stent placement (Table 2), the most common of which was for enteral feeding access.

Mean days from stent placement until repeat esophagraphy was $6 \pm 7$ days (range, 2-29 days; median, 4 days). The most common reason for delay of esophagraphy beyond 48 hours was continued mechanical ventilation. Occlusion of the esophageal fistula occurred in $20(95 \%)$ patients, as demonstrated by the initial esophagram. All 20 
Table 2. Surgical procedures performed in addition to esophageal stent placement

\begin{tabular}{lr}
\hline Associated surgical procedures & \\
\hline Tube jejunostomy & 10 \\
Tube thoracostomy & 5 \\
Percutaneous endoscopic gastroscopy & 4 \\
Thoracoscopic decortication & 4 \\
Tracheostomy & 3 \\
Celiotomy & 2 \\
Neck exploration & 1 \\
Total & 29 \\
\hline
\end{tabular}

patients were able to be started on an oral intake regimen, as outlined above. Polyflex stents in 20 (95\%) patients were removed without residual esophageal leak or fistula at a mean of $51 \pm 43$ days (range, 15-175 days). None of these patients required further operations for their esophageal fistula. Hospital length of stay varied widely because of the cause of the esophageal fistula and associated complications. The mean was $12 \pm 12$ days (range, 4-44 days; median, 7 days).

All stent placements occurred without intraoperative complications. One patient experienced the dehiscence of the esophageal perforation repair 2 days after stent placement and required operative repair. Other associated morbidities included respiratory failure $(n=5)$, pneumonia $(\mathrm{n}=2)$, and deep venous thrombosis $(\mathrm{n}=1)$, and 1 patient required celiotomy for an enterocutaneous fistula thought to be related to the original abdominal operation (Table 3). One (5\%) patient had an esophageal stricture after stent removal that required endoscopic dilatation. One (5\%) patient died from the rupture of an infected thoracic aortic graft after the reoperative repair of an aortic dissection complicated by esophageal perforation. This patient's esophageal injury was recognized and repaired by means of primary closure of the esophagus and pedicled muscle interposition at the time of the aortic dissection repair. When the leak recurred, endoluminal esophageal stent placement was performed. This patient's stent had been removed before death.

\section{Discussion}

The use of an endoluminal esophageal stent is not a new concept. Esophageal intubation has been used since the 19th century, when Symonds ${ }^{3}$ described his experience with prostheses made of ivory and silver. In more recent times, Mousseau and Celestin, and Atkinson and Ferguson have all developed devices for esophageal intubation. ${ }^{4-6}$ Difficulty with insertion, migration, and extraction, however, limited the use of these prostheses to the palliation of unresectable malignant conditions of the esophagus, with rare exceptions. $^{7}$
Table 3. Morbidities occurring after stent placement

\begin{tabular}{ll}
\hline Morbidities & \\
\hline Stent migration & $5(24 \%)$ \\
Respiratory failure & $3(14 \%)$ \\
Pneumonia & $2(10 \%)$ \\
Deep venous thrombosis & $1(5 \%)$ \\
Enterocutaneous fistula & $1(5 \%)$ \\
\hline
\end{tabular}

Taking advantage of the technology used to make endovascular stents, self-expanding metallic esophageal stents became available in the 1990s. These stents could be inserted with flexible esophagoscopy, required significantly less esophageal dilatation, had a lower rate of migration, and provided excellent palliation for malignant esophageal strictures. ${ }^{8}$ Subsequently, occlusive self-expanding esophageal stents were used to treat patients with malignant tracheoesophageal fistulae, as well as esophageal obstruction. ${ }^{9}$ The silicone covering decreased tumor ingrowth while forming an occlusive seal in the case of a fistula. However, there continued to be reluctance to place these prostheses in the esophagus of a patient for conditions other than palliative therapy for a malignancy because of the potential esophageal damage associated with extraction.

The recent ability to produce a plastic prosthesis coated with silicone has resulted in an esophageal stent that has a distinct advantage over previous versions. Ease of insertion, the requirement for minimal esophageal dilation, and the formation of an occlusive seal within the lumen of the esophagus are all similar to the self-expanding metallic stents. The distinct advantage of these nonmetallic endoprostheses is their unique ability to be extracted without damaging the esophagus. This has led some investigators to implant these stents in select patients as a temporary measure to treat an esophageal leak or fistula after esophagectomy. ${ }^{10}$

Patients who experience a continued leak or have an esophageal fistula after initial repair of an esophageal perforation or anastomotic dehiscence will most often experience a prolonged hospital course, realize a significant delay in their ability to take oral nutrition and hydration, and have the potential to experience localized infectious complications, as well as sepsis. The traditional treatment for these patients has been a reoperative attempt at repair or esophageal diversion with or without esophagectomy. On the basis of our anecdotal experiences using an occlusive, silicone-coated esophageal stent (Polyflex), we hypothesized that temporary esophageal stent placement could effectively treat some postoperative esophageal fistulae without the need for further esophageal operations.

This investigation reviews our experiences with a large group of patients treated in this manner. We found that endoluminal esophageal stent placement was easily accomplished. This resulted in the rapid closure of postoperative 
esophageal fistulae, eliminating this source of infection/ sepsis in all but 1 patient in this series. Although some patients could not attempt oral nutrition because of comorbid processes, patients who could otherwise tolerate an oral diet began one significantly sooner than would be expected after operative fistula repair. Finally, although difficult to quantify, it would appear that the 20 patients who were successfully treated with esophageal stent placement should have benefited from a reduction in the potential morbidity associated with another major surgical procedure. Similarly, a small percentage of these 20 patients could have required esophageal diversion with subsequent reconstruction, neither of which was realized because of endoluminal therapy.

These results are in keeping with 2 smaller series of patients with a postoperative esophageal anastomotic leak who received esophageal stent placement instead of operative repair. ${ }^{11,12}$ However, the current series is unique in both its size and the treatment algorithm used. Both previously reported series each contained significantly fewer patients than the series presented in this investigation. Furthermore, neither of the cited series treated a postoperative esophageal fistula definitively with surgical intervention, as was our standard, followed by endoluminal esophageal stent placement only if the fistula recurred. This strategy reflects the likely preference of the majority of thoracic surgeons and identifies a viable alternative to further surgical intervention.

The migration of these stents does minimally detract from their use. In this review 7 stents migrated in 5 patients, requiring repositioning or replacement. This compares favorably with other series in which esophageal stents have been used to palliate malignant strictures. ${ }^{13}$ However, we have recognized that this can be minimized by slightly oversizing the diameter and significantly oversizing the length of the stent when possible. Migration in our series was also more common in the proximal cervical esophagus and at the gastroesophageal junction, as would be expected because of the decreased surface area of the esophagus available to seat the stent.

Esophageal stricture formation after stent removal also occurred in $1(5 \%)$ patient in this investigation. This has been reported previously and appears to occur most often if the leak being treated is at the site of an esophagogastrostomy. In the series by Langer and colleagues, ${ }^{2}$ as well as in our experience, such strictures are easily treated without further surgical intervention and should not detract significantly from the use of these stents.

Similarly important to the success of treating patients with a postoperative esophageal fistula by using an esophageal stent is to achieve the same goals one would entertain if operative repair was performed. In addition to fistula occlusion, these include eliminating sources of infection/ sepsis, establishing reliable access for enteral nutrition, and minimizing postoperative morbidity. In this series patients required an average of 1.4 simultaneous procedures to accomplish these goals. We believe these associated procedures were integral to whatever success we might have achieved. In our opinion this global approach to these patients can only be provided with the involvement of and preferably under the direction of a thoracic surgeon.

Although it would appear that endoluminal esophageal stent placement for postoperative esophageal fistulae could have some advantages over further attempts at operative repair, this investigation has some weaknesses. Although representing the largest number of postoperative esophageal fistulae treated in this manner in the current literature, a patient population of 21 remains a small number, even for a relatively uncommon condition. Furthermore, no attempt was made to compare endoluminal therapy with reoperative therapy in either a prospective or retrospective fashion. It was believed that such a comparison would be of minimal benefit because of the significant variation in patients' comorbidities at the time the fistula was recognized, as well as the varied nature of their underlying esophageal diseases.

In conclusion, this series demonstrates the effectiveness of an occlusive esophageal stent in treating patients with recalcitrant postoperative esophageal fistulae. Endoluminal stent placement provides rapid fistula closure, eliminating soilage of the mediastinum, pleura and, peritoneum; allows patients to begin oral intake within 48 hours of stent placement; and eliminates the need for further operations in the vast majority of patients. Stent placement also offers an appealing alternative to reoperative repair and especially esophageal diversion and subsequent reconstruction. Proper patient selection and stent sizing should minimize the principle weakness of this treatment strategy: stent migration. The initial success demonstrated by this review might hold promise for treating selected postoperative esophageal fistulae, as well as iatrogenic esophageal perforations, with endoluminal techniques.

\section{References}

1. Lang H, Piso P, Stukenborg C, Raab R, Jahne J. Management and results of proximal anastomotic leaks in a series of 1114 total gastrectomies for gastric carcinoma. Eur J Surg Oncol. 2000;26:168-71.

2. Langer FB, Wenzel E, Prager G, Salat A, Miholic J, Mang T, et al. Management of postoperative esophageal leaks with a Polyflex selfexpanding covered plastic stent. Ann Thorac Surg. 2005;79:398-404.

3. Symonds CJ. The treatment of malignant stricture of the oesophagus by tubage or permanent catheterism. BMJ. 1887;1:870-81.

4. Mousseau M, Forestier J, Barbin J. Place de l'intubation a demeure dans le traitement palliative du cancer de l'oesophage. Arch Fr Mal Appl Dig. 1956;45:208-15.

5. Celestin LR. Permanent intubation in inoperable cancer of the esophagus and cardia: a new tube. Ann R Coll Surg. 1959;25:165-72.

6. Atkinson M, Ferguson R. Fiberoptic endoscopic palliative intubation of inoperable oesophagogastric neoplasms. BMJ. 1977;1:266-73.

7. Girardet RE, Ransdell HT, Wheat MW. Palliative intubation in the management of esophageal carcinoma. Ann Thorac Surg. 1974;18: 417-25. 
8. Moores DWO, Ilves R. Treatment of esophageal obstruction with covered, self-expanding esophageal wall stents. Ann Thorac Surg. 1996;62:963-9.

9. Song HY, Do YS, Han YM. Covered, expandable esophageal metallic stent tubes: experiences in 119 patients. Radiology. 1994; 193:689-93

10. Gelbmann CM, Ratiu NL, Rath HC, Rogler G, Lock G, Schölmerich $\mathrm{J}$, et al. Use of self-expandable plastic stents for the treatment of esophageal perforations and symptomatic anastomotic leaks. Endoscopy. 2004;36:695-9.

11. Hunerbein M, Stroszynski C, Moesta KT, Schlag PM. Treatment of thoracic anastomotic leaks after esophagectomy with self-expanding plastic stents. Ann Surg. 2004;240:8801-7.

12. Schubert D, Scheidbach H, Kuhn R, Wex C, Weiss G, Eder F, et al. Endoscopic treatment of thoracic esophageal anastomotic leaks by using silicone-covered, self-expanding polyester stents. Gastrointest Endosc. 2005;61:897-900.

13. Decker P, Lippler J, Decker D, Hirner A. Use of the Polyflex stent in the palliative therapy of esophageal carcinoma: results in 14 cases and review of the literature. Surg Endosc. 2001;15:14444-7.

\section{Discussion}

Dr Henning A. Gaissert (Boston, Mass). I have no disclosures.

To summarize, Dr Freeman and associates report 21 patients in whom acute postoperative esophageal leaks of fistulae were treated with a self-expanding Polyflex stent after failure of at least 1 operative repair. A seal was achieved in 20 of these 21 patients, and stenting lasted for a mean of 51 days. There were 3 complications. One patient died from disruption of an aortic repair, 1 patient had disruption of an esophageal repair, and 1 patient had a stricture.

I have 2 comments and several questions. The first point is that successful sealing of the leak is gratifying and important, but it is not the complete management of an esophageal leak. Other important components are the drainage of extraluminal fluid collections, decortication for pleural sepsis, and separation of the esophagus from adjacent structures, such as the aorta or airway, with vascularized tissue.

The second point is that self-expanding stents have important disadvantages related to the radial force necessary to maintain their position. If this radial force is too high, the stent erodes the mucosa and causes ulceration and stricture, and if it is too low, the stent slips and migrates, which occurred in $24 \%$ of patients. Placed across the esophagogastric junction, the stent might cause debilitating reflux and a stricture above. This treatment is therefore not without complications.

Now to my questions. There were 29 patients in the $2 \frac{1}{2}$ years with postoperative esophageal leaks and fistulae. I realize many of these were referred to you, but is there anything that you have learned in this period from the primary repair that would lead you to improve that management to decrease the need for stent intervention?

Second, do you trust the scar that results from stenting alone? I note that one of your patients had an erosion after an aortic repair through the aortic suture line, and there were 4 patients with airway fistulae, and I wonder whether in each of these patients you simply trusted the scar caused or occasioned after stent placement.

Third, there was an average of 6 days that passed before you knew whether the stent sealed the hole. That is a long time not knowing whether your management succeeded. Would you consider obtaining contrast studies at the time of stent placement?
This was a very nice article and very well presented, and I thank the Association for the opportunity to discuss it.

Dr Freeman. Thank you, Dr Gaissert.

You are correct in that only 3 of these patients came from our practice. The remaining patients either came from a gastroenterologist at our institution or were transferred in 16 cases. I think that looking at these patients brings to light the things that we are taught, that repairs should try and be without tension and to have some kind of vascularized tissue applied to them. We usually use muscle. In some of these patients, this had not been done initially and might have contributed to the failure.

As far as trusting the repair, we have had no problems with recurrent fistulae. That being said, 51 days was our mean time until stent removal, and I think we were very leery of taking these out too soon. In fact, we wanted to see excellent nutritional parameters in the patient and resolution of any infectious or septic parameter, including resolution of associated organ failure. Therefore I think we were very conservative when we removed these, and hopefully that has contributed to the lack of recurrence.

As far as knowing that the stent had sealed, to be honest with you, I think we have a pretty good idea of that at the time of stent placement. Because we were doing a study, we wanted a contrast esophagram for every patient. However, after stent placement, we obviously would perform another flexible esophagoscopy and would insufflate, and you get a pretty good idea that the leak has sealed if you have a chest tube in place, or if you have an airway fistula, you are going to do a bronchoscopy at the same time. Therefore I think some of the esophagrams were delayed because of the patients' other comorbidities, but in general, we usually knew that we had a good seal on leaving the operating room.

Dr Jonathan C. Nesbitt (Nashville, Tenn). Richard, I enjoyed your presentation. This is a difficult problem in a select cohort of patients, and I congratulate you on your results.

Dr Gaissert mentioned the problem with migration, and certainly I think with this particular stent it is one of the biggest issues, and, as you have shown, $24 \%$, that is a relatively high rate.

How do you size the stent, not only the diameter but also the length? Also, with regard to the actual perforation or the fistula, what do you believe is the optimal position, either high or low, in the esophagus for this particular stent? That is my first question.

Dr Freeman. We tend to oversize the diameter of the stent slightly and the length significantly, and we do that at the time of endoscopy by insufflating and also by using fluoroscopy. Therefore it is more of a feel. It also depends on where the fistula is located. Obviously you cannot do that if it is extremely proximal or extremely distal.

Dr Nesbitt. Certainly you cannot because the sizes vary significantly, and there is quite a difference between the diameters of each stent. The stents might slide and migrate, and sealing of the fistula or perforation is directly related to the stability of the stent position.

Dr Freeman. This article does not address acute perforations, but in these patients who have all had operations and some sort of repair, they do have more scarring, and I think you have a little bit of an advantage in that respect.

Dr Nesbitt. My next question pertains to the disparity between removal times of the stents. What do you believe is the optimal time for removal? 
Dr Freeman. Again, that is a very individualized decision. We were very conservative and still are. We like to see positive nitrogen balance, a good prealbumin value, resolution of any infectious or septic problems, and obviously no other signs of leak. We have had several persons in this series in whom we could actually monitor the healing either because it was an airway fistula or in one case a cervical esophagocutaneous fistula, and that made it a little easier, but it is a very individualized decision and it is based mainly on the patient's global status.

Dr Nesbitt. Finally, did you perform follow-up studies once you removed the stent, and if so, did you have any leaks, or did you have to replace the stent?

Dr Freeman. We performed esophagoscopy in the operating room before and after the removal of each stent, and a minimum of 24 to 48 hours after stent removal, the patients had another contrast esophagram. No patient had a residual leak or fistula in this series.

Dr Bryan F. Meyers (St Louis, Mo). Congratulations on your article.

You mentioned oversizing, and with these stents, if you oversize them too much, then you get an infolding at the top of the stent that is difficult to pop out, and then you are forced to stick a dilator or a balloon down there and blow up a balloon in a perforated or leaking esophagus. I just wondered whether you have encountered that problem. And just following up on the last question, how specifically would you pick the size to make it not migrate but make it not so large that you end up with an infolding and more of a tendency to leak around it?

Dr Freeman. In general, getting back to size, you really get a feel when you insufflate and distend the esophagus, and we generally go very large to make sure we have enough radial force to seal this, and I do not think we have used anything smaller than a size 25 in these patients. As far as the folding, that is a very frustrating problem. In early patients we would try and use a balloon dilator. The last few times that has happened, I basically left it alone and then did another examination in about 24 to 48 hours, and the fold comes out and opens up over time as the stent warms up.

Dr Rafael S. Andrade (Minneapolis, Minn). I commend you for trying to shift the therapeutic paradigm to this problem.

I have a question for you in terms of the esophagram. We have seen, particularly after an anastomotic leak, that the esophagram is negative in the upright position, but in the supine position contrast trickles distally around the stent and out of the fistula. Now, that is not necessarily a failure because you might still be slowing down the leak and eventually the patient will do well. I want to have your opinion on how you are doing your esophagrams after stent placement.

Dr Freeman. First of all, I think that hopefully has been a minimal problem because we do oversize significantly in diameter of the stent. We do wait generally a minimum of 48 hours before we do an esophagram, and they do a standard esophagram, which is sitting and lying down, and it is a video esophagram.

Dr Stephen G. Swisher (Houston, Tex). As you know, there is a variation in severity of esophageal leaks, and I was just wondering whether you could comment on how many of these leaks were contained and how many were free flowing, and how many of these patients were septic or were looking pretty good?

Dr Freeman. One indication of how sick they were is that most of them were transferred from other places. They were critically ill. Their leaks were, for the most part, drained, at least into the pleural or peritoneal space. These were not small, contained postoperative leaks that just needed a few more days to heal. These were fairly significant leaks, and I think you can tell that also by the associated procedures that we had to do to try and remove areas of infection.

\section{The Journal of Thoracic and Cardiovascular Surgery Conflict of Interest Policy}

To assure fairness to authors submitting work for consideration in The Journal of Thoracic and Cardiovascular Surgery, a mechanism exists for managing conflicts of interest. The editor and each of the section editors complete a "Conflict of Interest" form that identifies any and all relationships with commercial and other academic entities. When the editor has a potential conflict because of a relationship with another entity or author, the editor appoints an alternate editor from among the section editors or editorial board members who assumes the entire responsibility for final decisions on the manuscript in question. The editor does not read the reviews that are submitted nor engage in discussing the manuscript prior to the final decision. When the conflict of interest involves a section editor, a "guest section editor" is appointed who fills the role normally played by the conflicted section editor. All members of the editorial board and reviewers are asked to indicate any conflict of interest when they agree to review a manuscript. 